\begin{tabular}{c} 
Volume and Issues Obtainable at Center for Sustainability Research and Consultancy \\
Journal of Accounting and Finance in Emerging Economies \\
ISSN: 2518-0318 ISSN (E) 2518-8488 \\
Volume 6: Issue 2 June 2020 \\
CSRE \\
Journal homepage: www.publishing.globalcsrc.org/jafee \\
\hline
\end{tabular}

\title{
Social Inclusion of Disabled Persons: Role of a Professional Social Worker in Pakistan
}

\author{
${ }^{1}$ Syeda Mahnaz Hassan, ${ }^{2}$ Aliya Khalid, ${ }^{3}$ Muhammad Arshad, ${ }^{4}$ Shajiah Qursam \\ ${ }^{1}$ Chairperson, Department of Social Work, University of the Punjab, Pakistan, drsyedamahnazhassan@ gmail.com \\ ${ }^{2 \& 3}$ Assistant Professor, Department of Social Work, University of the Punjab, Pakistan \\ ${ }^{4}$ MPhil Scholar, Department of Social Work, University of the Punjab, Pakistan
}

\begin{abstract}
ARTICLE DETAILS
History

Revised format: May 2020

Available Online: June 2020

\section{Keywords}

Social Inclusion, Person with

Disabilities, Professional

Social Worker, Pakistan's

Community
\end{abstract}

JEL Classification

G01, G12

\begin{abstract}
This paper aims to explore the role of professional social workers in the social inclusion of disabled persons in Pakistan. This paper highlights the present scenario of social work practice with the disabled community and how professional social workers are bringing social inclusion of disabled persons by working effectively in the field. The data for this study was collected through qualitative approach. The semi-structured interview guide was used to collect data through in-depth interviews from thirteen professional social workers who are working for the social inclusion of persons with disabilities in Pakistani community. Thematic analysis was used to analyze the data. The data revealed that social workers have enough abilities to create a bridge between disabled persons with their community. There are different sources present in the community which can be utilized by professional social workers to enable disabled persons to live a normal life. Unawareness of common people and government towards the roles of social workers has been observed in this study. Enhancement and encouragement of social work practice in the field of disability is particularly needed.
\end{abstract}

\section{OPEN ACCESS}

(C) 2020 The authors, under a Creative Commons Attribution-

NonCommercial 4.0

Corresponding author's email address: drsyedamahnazhassan@ gmail.com

Recommended citation: Hassan, S. H., Khalid, A., Arshad, M. and Qursam, S. (2020). Social Inclusion of Disabled Persons: Role of a Professional Social Worker in Pakistan. Journal of Accounting and Finance in Emerging Economies, 6(2), 643-649

\section{Introduction}

Disability means an inability to perform an activity due to any impairment in the body (WHO, 1980). Social inclusion does not have a single and perfect definition but it can be defined as an approach through which the participation and mainstreaming of normal life activities of the marginalized group could be possible (Stevens et al. 1999; Hill et al. 2004). Social inclusion of persons with disabilities is defined at a vast level in the field of social work. From the beginning, it is not an easy task for a disabled person to lead a normal and independent life. They could not get a reputable status in the society due to the stigmas present in society for them (Mackelprang \& Salsgiver, 1996).

Due to exclusion from society, people with disabilities had to face some problems like illiteracy, unemployment which lead them toward poverty and discriminated attitudes of people towards them. The disability remained a 
debated issue until three models; medical model, moral model, and social model came into being (Mackelprang \& Salsgiver, 2009). These models assist the society to change their attitudes towards the disabled community, which could help them to be a normal part of society.

It is presented by the United Nations that fifteen percent of the worlds' population has any kind of disability and it is rising continuously (World Health Organization, 2011). Social workers are in contact with persons with disability from the beginning of the profession. They always consider them as a normal and productive part of the community and welcome them without any discrimination.

Universally, professional social workers are working in the field of disability and are aware of the special needs and training of disabled people to make them a productive part of society. "The National Association of Social Workers" declares that it the moral obligation of social workers to work with disabled communities and play the role of their advocate towards society (National Association of Social Workers, 2006). Disability is also a significant part of the education of social work which became the agenda of the "Council on Social Work Education" (CSWE, 2008).

In various countries of the world, social work is firmly associated with the concept of disability. In the United States, about eighty percent of schools are educating the role of the social work profession in the area of disability (Brean \& Kreek, 2012). In South Asian countries, disability is linked with traditional and western beliefs. Disabled persons face social barriers and discrimination in family and in society as well (Daudji et al., 2010). Disability in South Asian countries is an essential area and it is facing a crucial time at this moment. The development of this part is needed in these countries. There is a need for critical thinking and activism of social work in South Asian countries (Ghai, 2018).

Disability can attack at any age and at any moment to an individual (Murphy \& Carbone, 2011). Due to rapid growth in the population of disabled persons, the department of special education is significantly attached to the area of disability in Pakistan. They are more focused on education-related to special persons. Special education is increasing the numbers of trainers and educators in their field. But there is a vital role of the social work profession in the inclusion of persons with disabilities in the Pakistani community. The social work profession focuses more on the potential and aptitude of the client and provides them strength on the basis of their instincts to be a beneficial part of society (Galambos, 2004).

In Pakistan, the estimated number of disabled persons given by the "Pakistan Bureau of Statistics" are 3.3 million. This figure represents the registered disabled persons according to the census of 1998. Pakistan has sanctioned the CRPD to defend the rights of people with disabilities. Persons with disabilities in Pakistan have to face restraints in the physical and social environment. There is no proper informational data about people with disabilities. Disabled persons have to face exclusion from normal functioning and mainstreaming in society. There is only one law for disables named as, "The Disabled Persons (Employment and Rehabilitation) Ordinance 1981" (Ahmed. T, 1993).

A report was presented by the British Council on Moving from the margins: Mainstreaming persons with disabilities in Pakistan in 2014. They reported that there are twenty-seven million disabled persons in this country. Pakistan is still on the way to fulfill the promises of the UN conventions about the disabled community. This report highlighted the need for interventions in the strategy-making for disabled and awareness about disabled community is required in Pakistan.

\section{Literature Review}

Disability is always considered as the displeasure of God towards a person or its family. It makes them isolated from society and society considers them as a curse. Due to exclusion, disabled persons have to be dependent on charity to meet their necessities for livelihood (Mackelprang, 2010). Although social work is contributing to persons with disabilities for a long time, "Americans with Disabilities Act" brought an opportunity for the social work profession to get significance in the area of disability (Quinn, 1995).

Trevillion (2006) has discussed that developed countries have renewed the concept of social work with disability 
because there was destruction in accordance to give welfare to a person with disabilities. The concept of disability moved slowly from narrow to broader perspectives. This paper elaborates that, with respect to giving social care services England is now using a "person-centered" approach. The social model of disability is utilized by social workers to give welfare services to disabled persons. Social workers are now giving rise to social work practitioners in the field of disability.

In Australia, social work practice has a great influence on market values and other human services. Through the lens of modern social work, disability is considered a social relationship not as a trait of a single person. The whole society is playing its role while growing a disabled person in a particular environment. According to this view, the need for the social work profession is much more in society to create a bridge between society and the oppressed person or group. In Australia, disability is an important matter for Public Affairs, and it is considered a responsibility of the state to ensure their inclusion (Meekosha \& Tamp; Dowse, 2007).

The concept of disability and disabled persons are not welcomed in developing countries due to the slow progress of thoughts and concepts. It takes years to bring a social change in developing countries than in developed countries. The modern concepts related to disability are like an illusion for disabled communities in South Asia. There is a need to rediscover the disability arena in South Asia. The approaches for people with disabilities are ancient and outdated. The particular authorities or persons working with this oppressed community are not well equipped and skilled enough (Miles, 1997).

Pakistan, as a part of South Asian countries and having major cases of disability, faces connotations in this field. Rathore, New, \& Iftikhar, presented a study in 2011 in which they presented a picture of the social and medical conditions present in the country for a disabled person. They have discussed that in Pakistan people with disabilities have to face stigmatization and discriminated attitude from society which does not let them be adjusted and become fit part of their society. It was an electronic survey because there is no clear picture present in this country to highlight the exact numbers and conditions of people with disabilities which shows it is a neglected part of the society. A person with disabilities is only known through special education. But for their welfare, there is no special system present.

Galambos (2004) has discussed in his research that, throughout the history of US, the rights of disabled were advance. Discrimination against disabled community is illegal. Legislative initiatives were considered as the beginning of civil rights movement for disabled but American Disability Act (ADA) is the benchmark for the provision of rights to persons with disabilities. He further added that, social work profession is the best profession for delivering the services to marginalized segments of the society because social work is the practice-based profession. Combination of person-centered planning and strength-based profession can bring interventions in the field of disability social work.

\section{Methodology}

This research is based on the descriptive qualitative research method. The tool of data collection used in this study was semi-structured interview guide. The data has been collected through purposive sampling from professional social workers working with the disabled persons. The total sample of this study included thirteen respondents. The contact was made to them personally in their professional settings. It took about one month to collect the data and each interview took forty to sixty minutes. The data was collected in the Urdu language which further has been translated into English language. All the interviews were audio-recorded with the consent of the respondents. All the recorded interviews were then transcribed by the researcher. Then the primary data was analyzed by the researcher using thematic analysis.

\subsection{Role of Social Workers in the Social Inclusion of Persons with Disabilities at Community Level}

The disabled community in Pakistan is suppressed in the society. The myths about disability in society are not letting the disabled persons become a normal part of society. A professional social worker is the social scientist of society. That's why social workers can play the roles of awareness-raisers, broker, and motivator at the community level to enhance the social inclusion of disabled persons. 


\subsubsection{Awareness Raising}

In Pakistani culture, a person with any disability is supposed to be cursed by God or people think that the child is the punishment of sins of their parents. Moreover, they consider them a segregated part of society and make discrimination with them. At this point, one of the professional social workers expressed his views on how to raise awareness.

"Whenever they go outside on wheelchair or holding sticks. People make their amusement. They call them "Langra" and inappropriate wording like this. It is the worst thing. I feel sorrow and pain. I think, first of all, the social worker must educate our society. The social workers can create awareness in the society very well. Because the social worker knows how to talk and what to talk. It is the obligation of the social workers to raise voice for disabled people in their own community."

\subsubsection{Broker}

The professional social worker has the ability to create a bridge on the present gap between the oppressed communities with the society to make them a natural and normal part of society. The social workers can make favorable circumstances for disabled persons in their community. One of the respondents said:

"Social Worker can play its role thereby creating a friendly atmosphere for them at their hometown or village. Like if a disabled person wants to go to the mosque then being a Social Worker it is my responsibility to provide him the facility of ramp or slope to get him into the mosque. Similarly, if we are present at a place where we see children with hearing impairment or blindness then it's our responsibility to be a Social Worker to create a friendly atmosphere for them. To which we called barrier-free society for special persons."

\subsection{Motivator}

Social worker has a vast and diverse perspectives of their community and social worker has abilities to use the selfdetermination of a person to deal with the constraints and make them able to adjust in the society. A respondent elaborated this role by saying;

"We work with disabled people with the motivational approaches. Foreign countries are following these patterns. I also visited some countries. When we utilize motivational approach then it creates a sense of responsibility among people and it boosts up the morale of disabling child. When we will inject a sense of responsibility in people, then society will become helpful towards these disabled persons. Our society needs modification. We need to motivate them to be more trained, more literate, and more educated about disabled community."

\subsection{Role of Social Workers in the Social Inclusion of Persons with Disabilities at the Administrative Level}

A professional social worker has to play complex roles in social work organizations while working as an administrator, because the administrator is the core member to run the whole project or in providing social welfare services. Advocacy could be done by a social worker for the provision of better services. The social workers can guide better to the disabled person and it is the role of the social worker to evaluate the given services for betterment.

\subsubsection{Advocate}

As an expert administrator of a professional setting, social work is equipped with strong communication skills to advocate for oppressed. Social worker deals with the marginalized community with empathy, that is why, no one else could advocate for disabled persons with policymakers and community to bring social inclusion of persons with disabilities. While defining this major role, one of the respondents said:

"Social Worker can play the role of advocate for disables. As he is more close to persons with disabilities and the community, he is working in. If we see ourselves then we work closely with the NGOs. For example, if an NGO has 50 disables then a Social Worker can reach these 50 disables via one NGO only. 
We can advocate for disabled to the government for their rights and provision of services which will help them to make suitable policies for them. If the government will have a proper mechanism and system having proper policies, then we can implement those policies greatly and on the right persons."

\subsubsection{Guide}

Social workers are working closely with services related to people with disabilities. They are well aware of all the services and benefits are given by the government. In this condition, no one else could be a good guide than a professional social worker to disable people in order to get access to the right help and aid. This role was well defined by a professional social worker:

"We provide different types of services like technical assistance and guidance. We also provide them tangible services like wheelchairs. In case of any problem or further requirement we refer them to NGOs and give them proper guidance about the benefit, they could get at that place. Because they do not know about the services present for them. And in case of medical problems we guide them about specific hospitals or the NGOs who are working for the medical relief of disable persons. Other than we give them information about incentives they can get from the government as well."

\subsubsection{Evaluator}

In order to provide social services under the umbrella of the social work profession, evaluation is an essential part of the process. Evaluation is needed by an expert evaluator in practicing social work and providing social services. Evaluation can improve the effectiveness of the services and can bring interventions in policymaking according to the need of the society and persons with a disability. One of the respondents explained the importance of evaluation in words as:

"Social Worker can promote the social inclusion of persons with disabilities well at the state level. He/she can easily evaluate the current policies for them and the actual condition of disables in their community. Social workers must be a part of policymaking because from there they can bring social inclusion after research. There are many forums where social workers can utilize their knowledge to promote social inclusion of disables like at home, mohallas, and at their job place after observing the current situation and then what change they could make at the present situation."

The social work profession can give social support and bring social inclusion of the oppressed sector of society. Social inclusion of disabled persons is more necessary in the Pakistani community because it will allow disabled persons to participate fully in society. In this regard, a professional social worker is the best person that can bring social inclusion and will cause a social change in Pakistani society.

\section{Discussion}

This study explained that the social inclusion of persons with disabilities in Pakistan is needed. The concept of social inclusion of disabled persons is still an alien concept in the Pakistani community. Millions of disabled persons are living abnormal and discriminated life here. Due to false beliefs and unawareness about the concept of disability, makes them the segregated section of the community. The person with a disability is unable to perform like a normal person but with suitable help and guidance, he/she could utilize the disability in a productive sense. The role of a professional social worker is essentially required to ensure the inclusion of persons with disabilities. Because social workers are aware of the demands and specific needs of the disabled persons in their respective communities. Professional social workers have the ability to understand and then address the problems of a person with disabilities at the concerned platform. Professional social workers who are in contact with disabled community knows and understands their problems. Moreover, they are known to the concept of disability. According to the social work profession, they are providing social assistance and aid to disabled persons (Meekosha \&amp; Dowse, 2007). Social inclusion means the proper guidance and support to disabled persons by utilizing their own abilities and strengths. The social worker has the ability to use limited resources of the community and tendency to generate or moderate the present resources according to the need and demand. For this purpose, social inclusion could be effectively applied 
through professional social workers. Social workers know the client (person with a disability), community, and the system which is providing assistance to the person with disabilities. This task can only be done by using the effective roles of the social workers to make alignment between person, place, and system (Trevillion, 2006). By using contemporary social work practices, a professional social work can apply the approach of social casework on the client ( disabled person), group work could be done by working in the community and family of the concerned client and this will lead to community development through a proper organization which is the professional setting of a caseworker.

Professional social workers can play their roles at micro and macro level for the social inclusion of disabled persons. In micro level practice, social worker may work with an individual or groups. Counselling of the oppressed individual and family attached to him/her by social worker will help them improve their functioning and adjustment in the concerned society (National Association of Social Workers). At micro level, case management, skill development, vocational supports and residential support can be provided by a professional social worker to the persons with disabilities.

At macro level, social workers play their roles to bring social development, equality and social justice for disabled persons. Persons with disabilities face difficulties in obtaining education, employment, housing and incentives. Social workers who are working at macro level bring social policy and advocacy programs for persons with disabilities to ensure their rights and mainstreaming in the society. Social workers can play their major roles by working with different governmental and non-governmental agencies to integrate and promote policies, advocacy and empowerment practices of this oppressed population.

Professional social workers deal with the individuals with disability and the community of the oppressed. Active listening and observation are the most effective roles of a social worker and after observing the situation a social worker can help the oppressed by using the emotional intelligence. Development model can be used in disability social work, in which an individual has to pass the stages of development sequentially. In this process, path is one, but it has stages. A disabled person can be placed at one stage according to the need. In the developmental process of individual with disability, the social worker plays his/her required role at each stage. Social worker plays role from individual to social level for the social inclusion of persons with disabilities and make them enable to live a normal life in the society.

\section{Conclusion}

Disability content in social work in Pakistan is taught and professional social workers are well aware of it. The person with disabilities is excluded from society due to outdated myths and are not encouraged by attitudes of people of the society. There is a need for social workers in the area of disability to apply its inclusion bringing practice, research, and evaluation in the practice will lead towards policy changing and it will eradicate the social exclusion of disabled persons. Moreover, the persons with disabilities are not registered at the state level which is making them unrecognized in the eyes of the government. Due to this, the government is unable to do maximum help for the inclusion of disabled persons. Furthermore, besides special education, there is a need for skills-based education too to make them productive for themselves and for society as well. Social work practice with disabled will not let them a burden to society but will facilitate them to become a beneficial part of the society.

These steps will result in social inclusion of a major suppressed group of society and will help in the development of a person with disability and social work profession in Pakistan. There is potential in the social work profession and in professional social workers to work at a platform where social workers can work effectively to bring contemporary social work practices in Pakistan and could promote the social inclusion of persons with disabilities.

Social work profession has rooted ethical standards which are based on spirituality and social values that have supported the social service system. By utilizing these standards, social workers can work effectively in the field of disability to achieve effective results in Pakistani Society. Social workers use human rights-based approach towards disabled persons which promote the change in paradigms and contribute to bring social change towards inclusion of disabled in the society. 


\section{References}

Ahmed, T. (1993). Disabled population in Pakistan: Disabled statistics of neglected people. Sustainable Development Policy Institute.

Bean, K., Krcek, T. (2012). The integration of disability content into social work education: An Examination of infused and dedicated models. Advances in Social Work, 13(3), 633-647.

Ghai, A. (2018). Disability in South Asia: Knowledge and experience. New Delhi, India: SAGE Publications India, Pvt.

Galambos, Colleen M. (2004). Social work practice with people with disabilities: Are we doing enough? Health \& Social Work, 29(3), 163-166.

Hill, M., Davis, J., Prout, A. \& Tisdall, K. (2004) Moving the participation agenda forward. Children and Society, 18, 77-96

Mackelprang, R., \& Salsgiver, R. (1996). People with disabilities and social work: Historical and contemporary issues. Social Work, 41(1), 7-14.

Mackelprang, R. W. \& Salsgiver, R. O. (2009). Disability: A diversity model approach in human service practice. Chicago: Lyceum Books.

Mackelprang, R. W. (2010). Disability Controversies: Past, Present, and Future. Journal of Social Work in Disability \&amp; Rehabilitation, 9(2-3), 87-98.

Meekosha, H., \& Dowse, L. (2007). Integrating critical disability studies into social work education and practice: An Australian perspective. Practice, 19(3), 169-183.

Miles, M. (1997). Disabled learners in South Asia: Lessons from the past for educational exporters. International Journal of Disability, Development and Education, 44(2), 97-104.

National Association of Social Workers. (2008). Code of Ethics. Retrieved from http://www.naswdc.org/pubs/code/code.asp

Quinn, P. (1995). Social Work and Disability Management Policy:. Social Work in Health Care, 20(3), 67-82.

Rathore, F. A., New, P. W., \&amp; Iftikhar, A. (2011). A Report on Disability and Rehabilitation Medicine in Pakistan: Past, Present, and Future Directions. Archives of Physical Medicine and Rehabilitation, 92(1), 161166.

Stevens, A., Burr, A.M. \& Young, L. (1999) Partial, unequal and conflictual: problems in using participation for social inclusion in Europe. SocialWork in Europe, 6, 2-9.

Trevillion, S. (2006). Critical Commentary: Health, Disability and Social Work: New Directions in Social Work Research. British Journal of Social Work, 37(5), 937-946. doi:10.1093/bjsw/bcm075 